\title{
Proactive inhibition involving maze habits
}

STANLEY RICKARD ${ }^{1}$

NORTHWESTERN UNIVERSITY

\begin{abstract}
On successive days each of 84 rats learned reverse spatial discriminations in a T-maze. Each rat was then given five test trials without reinforcement at one and only one of the three retention intervals--one hour, one day, and one week. Contrary to theoretical expectations, the relative strength of the first-learned discrimination was not greater at the longer retention intervals.

Theory

Forgetting is explained by one prominent theory (Postman, 1961) in terms of the interference of competing responses. The theory holds that as a $\mathrm{S}$ learns a response, competing responses already in his repertoire undergo extinction. These extinguished responses do not, however, remain weak. As time passes they recover more and more of their original strength and thereby interfere increasingly with the execution of the learned response. Thus, the learned response is forgotten; that is, it is elicited less and less often by the stimulus conditions to which it was originally associated.

Experiments in verbal learning employing an A-B, A-C paradigm have offered support for the theory (Adams, 1961; Barnes \& Underwood, 1959; Briggs, 1954), but animal studies have sometimes supported the theory (Gleitman \& Jung, 1963) and sometimes not (Gleitman \& Steinman, 1963; Kehoe, 1963). In the present study, rats learned a simple spatial discrimination in a T-maze. On successive days each rat was taught competing habits. The relative strengths of these habits was then determined at different retention intervals. According to interference theory, the frequency of first-learned habits at different intervals should be directly related to interval length.

\section{Procedure}

Each of 84 female white rats participated in the experiment after one week of handling, scheduled feeding, and pellet training. Under the feeding schedule, they were given about $10 \mathrm{gm}$ of standard laboratory chow at about 2:00 P.M. each day and were allowed to eat as much of it as they could during the subsequent $2 \mathrm{hr}$.

On the basis of their order of arrival at the laboratory, the rats were assigned to training squads of three rats each. The rats within each squad were randomly assigned to the three testing intervals of one hour, one day, and one week with the restriction that one squad contain no more than one representative of each interval.

Two days of the experiment were devoted to the training of each squad. On the first day, the rats within a squad were taught either a right turn or a left turn in a T-maze, and on the second day, they were taught the opposite turn. The criterion of learning was nine correct choices out of 10 consecutive trials. A dark gray, wooden $\mathrm{T}$-maze with a Plexiglas roof was used. The training period each day began about $20 \mathrm{hr}$, after the feeding period the previous day. The ordering of rats on each day of training was random. The order of the trained turns, either left-right or right-left, was counterbalanced throughout the experiment.

On each trial, Ss were left in the goal box for 15-20 sec. after committing themselves to either a corrector an incorrect turn. The reinforcement for a correct turn was one pellet. The intertrial interval was 25-30 sec.

Between training and testing, Ss were maintained on the feeding schedule but were not fed pellets or handled. Five test trials were given each rat at an hour, day, or week (depending on its assignment to a testing interval) after reversal learning. During these test trials no turn was reinforced.

Since the one-hour interval rats ate about 15-20 pellets in the course of learning their second turns, the one-day and one-week animals were given food one hour before testing. Within each squad, the number of pellets that the one-day and one-week animals received was determined by the number of pellets consumed by the one-hour rat during the second day of training. Results

There was considerable loss of Ss due to the requirement that they reach the criterion of learning in one day. Altogether, six were lost from the one-hour group, five from the one-day group, and four from the one-week group.

Analyses of variance were performed on the trials through criterion scores obtained on both days of training. For the one-hour, one-day, and one-week groups, the mean scores were $35.82,33.00$, and 33.58 respectively for the first day and 23.50, 22.26, and 20.08 respectively for the second. The F's of .38 and 1.90 $(2,66)$ were insignificant at the .05 level.

Table 1 presents the frequency of first-day and second-day habits during the five testing trials. An analysis of variance was performed on the scores based on the number of second-habit choices made by each $\mathrm{S}$ during his five testing trials. The mean numbers at one hour, one day, and one week were $3.77,3.57$, and 3.42 respectively. The $\mathbf{F}(2,66)$ of 1.64 was not significant at the .05 level. Comparison of the proportions of first- and second-learned habits at the different testing intervals was also made for individual testing trials. The $\chi^{2}$ 's obtained for trials one and two were 1.23 and 
TABLE I

Frequency of Occurrence of First- and SecondLearned Responses on Test Trials

\begin{tabular}{|c|c|c|c|c|c|c|}
\hline \multicolumn{7}{|c|}{ All Groups } \\
\hline \multicolumn{7}{|c|}{ Retention Interval } \\
\hline \multirow{2}{*}{$\begin{array}{c}\text { Trial } \\
\text { Number }\end{array}$} & \multicolumn{2}{|c|}{ One hour } & \multicolumn{2}{|c|}{ One day } & \multicolumn{2}{|c|}{ One week } \\
\hline & $\begin{array}{l}\text { First } \\
\text { learned }\end{array}$ & $\begin{array}{l}\text { Second } \\
\text { learned }\end{array}$ & $\begin{array}{c}\text { First } \\
\text { learned }\end{array}$ & $\begin{array}{l}\text { Second } \\
\text { learned }\end{array}$ & $\begin{array}{c}\text { First } \\
\text { learned }\end{array}$ & $\begin{array}{l}\text { Second } \\
\text { learned }\end{array}$ \\
\hline 1 & 5 & 17 & 9 & 1.4 & 7 & 17 \\
\hline 2 & 8 & 14 & 4 & 19 & 7 & 17 \\
\hline 3 & 5 & 17 & 6 & 17 & 7 & 17 \\
\hline 4 & 7 & 15 & 8 & 15 & 9 & 15 \\
\hline 5 & 2 & 20 & 6 & 17 & 8 & 16 \\
\hline Total & 27 & 83 & 33 & 82 & 38 & 82 \\
\hline $\mathrm{n}$ & 22 & & 23 & & 24 & \\
\hline Mean & 1.23 & 3.77 & 1.43 & 3.57 & 1.58 & 3.42 \\
\hline
\end{tabular}

2.01 ; with $2 \mathrm{df}$, a value of 5.99 is required at the .05 significance level. Thus, for the first two trials and for all the trials combined, the hypothesis could not be rejected that differences in the proportion of these habits at different retention intervals was a chance phenomenon.

Diseussion

It is possible that there was some recovery of firstlearned habits during the hour after reversal learning. At the one-hour retention interval, $25 \%$ of the responses were those learned on the first day of training. Perhaps the criterion of learning on the second day of training, which was only nine correct out of 10 trials, is adequate to explain this proportion.

In concurrence with some other animal studies, the present experiment fails to demonstrate any forgetting attributable to the recovery of interfering responses. Since the interference theory of forgetting evolved in a verbal learning setting, these animal studies are unsupportive only to the extent that their procedures are analogous to those employed in studies on verbal learning.

\section{References}

Adams, S. Temporal changes in the strength of competing verbal associates. Unpublished doctoral dissertation, University of California, Berkeley, 1961. Cited by L. Postman, The present status of interference theory. In C. N. Cofer, (Ed.), Verbal learning and verbal behavior. New York: McGraw-Hill, 1961.

Barnes, J. M., \& Underwood, B. J. "Fate" of first-list associations in transfer theory. J. exp. Psychol., 1959, 58, 97-105.

Briggs, G. E. Acquisition, extinction, and recovery functions in retroactive inhibition. $J$. exp. Psychol., 1954, 47, 285-293.

Gleitman, H.., \& Jung, L. Retention in rats: The effect of proactive interference. Science, 1963, 142, 1683-1684.

Gleitman, H., \& Steinman, F. Retention of $r$ unway performance as a function of proactive interference. J. comp. physiol. Psychol., $1963,56,834-838$.

Kehoe, J. Effects of prior and interpolated learning on retention in pigeons. J. exp. Psychol., 1963, 65, 537-545.

Postman, L. The present status of interference theory. In C. N. Cofer, (Ed.), Verbal learning and verbal behavior. New York: McGraw-Hill, 1961.

\section{Note}

1. The author wishes to express his gratitude to Professors W. F. Hill and B. J. Underwood for their counsel. 